\title{
Increasing case numbers of adenovirus conjunctivitis in Germany, 2010
}

C Adlhoch (adlhochc@rki.de) ${ }^{1,2,3}$, I Schöneberg', G Fell4, D Brandau4, J Benzler ${ }^{1}$

1. Robert Koch Institute, Department for Infectious Disease Epidemiology, Unit for Surveillance, Berlin, Germany

2. Postgraduate Training for Applied Epidemiology (PAE, German Field Epidemiology Training Programme), Robert Koch Institute, Department for Infectious Disease Epidemiology, Berlin, Germany

3. European Programme for Intervention Epidemiology Training (EPIET), European Centre for Disease Prevention and Control (ECDC), Stockholm, Sweden

4. Institute for Hygiene and the Environment, Hamburg, Germany

Citation style for this article:

Adlhoch C, Schöneberg I, Fell G, Brandau D, Benzler J. Increasing case numbers of adenovirus conjunctivitis in Germany, 2010. Euro Surveill. 2010;15(45):pii=19707. Available online: http://www.eurosurveillance.org/ViewArticle.aspx?Articleld=19707

Article published on 11 November 2010

In 2010 (as of 13 October 2010), the number of adenovirus conjunctivitis cases reported to the Robert Koch Institute in Berlin, Germany, has increased by more than $250 \%$ compared with same period in the previous two years. An investigation was initiated to identify spatial or temporal clusters, possible sources of infection and potential connections to cases abroad. The analysis did not show a disproportionately affected sex or age group, but many infections were preceded by exposure to ophthalmological facilities, communal facilities or public places.

\section{Background}

Several reports have recently been posted in ProMED of viral conjunctivitis in various parts of the world [1-7]. Since the beginning of 2010 , there has been a rise in the number of notified cases of adenovirus conjunctivitis in several German Laender. The Robert Koch Institute (RKI) in Berlin initiated an investigation of all notified cases in the country in order to identify spatial or temporal clusters of cases, any potential connection to cases abroad and possible sources of infection, so that appropriate public health measures could be recommended.

Adenoviruses are non-enveloped double-stranded DNA-viruses, which are resistant to various treatments (e.g. extremes of $\mathrm{pH}$ ) and are therefore difficult to inactivate. They can be transmitted via contaminated hands or objects, often in healthcare settings. Depending on the serotype, clinical manifestations are related to different organ systems, such as the eye and the respiratory or gastrointestinal tract, resulting in diverse clinical pictures. The most frequently detected human adenoviruses (HAdV) found in conjunctivitis are of serotypes 8, 19 and 37 [8].

Adenovirus conjunctivitis is characterised by sudden onset of symptoms and can be diagnosed clinically by keratitis with coin-shaped infiltrations in the cornea. It is usually self-limiting. The incubation period generally lasts from five to 12 days and the person remains infective for up to three weeks. Diagnosis can be laboratory confirmed by direct detection of the pathogen (by polymerase chain reaction (PCR), immunoassays or cell culture). As only the symptoms can be treated, good hygiene and disinfection management are therefore important for prevention and control of the disease $[9,10]$.

\section{Case notification}

In Germany, notification to local health authorities is mandatory for laboratories that detect adenoviruses from conjunctival swabs (direct detection of antigen or DNA) [11]. Case data, including data on epidemiological links, is then reported to Robert Koch Institute according to the national case definition. The German notification system has been described previously [12].

Notified cases in 2010 (up to 13 October 2010) in Germany were analysed and compared with the two previous years regarding temporal and spatial distribution. Clusters were defined as epidemiologically linked cases with a minimum of two persons, whereas sporadic cases had no documented link to other cases.

We asked all cases notified from weeks 34 to 40 (i.e. over the previous six weeks) from six Laender whether they would be prepared to be interviewed, using an exploratory questionnaire, in order to generate a hypothesis of common infection modes or sources. Selecting weeks 34 to 40 allowed us to obtain a sufficiently large sample size and given the cases were recent, recall bias was minimised.

\section{Analysis of notified cases}

As of 13 October 2010, 370 persons with adenovirus conjunctivitis with onset of symptoms from 1 January 2010 were notified to local health authorities and reported to the Robert Koch Institute. The date of symptom onset was recorded for 303 , while in a further 67 cases it was assumed to be in 2010 due to the time 
of notification. During the same time period in 2008 and 2009, 141 and 134 cases respectively were notified (the total number of notified cases was 180 in 2008 and 169 in 2009). In those years, the infections were distributed widely, affecting urban and rural districts, with the highest number of cases occurring in August.

In 2010, the median and mean age of cases was 39 years (range: 0-90 years). A total of $186(50 \%)$ were men (in 2008: $47 \%$; in 2009: $51 \%$ ). Cases were notified in all Laender, from laboratories to local health authorities in 121 rural and urban districts (30\% of all districts). Cases were mainly clustered in northern Germany (whereas in 2009, they were more evenly distributed). The highest incidence was found in Mecklenburg-WestPomerania (in the north-east of the country) with five cases per 100,000 population (Figure 1, Table 1). The highest number of cases was reported in week 13 (the week before Easter) (Figure 2). The appearance of cases

\section{FIGURE 1}

Geographical distribution of notified adenovirus conjunctivitis cases ${ }^{\mathrm{a}}$, Germany, 2010 $(\mathrm{n}=370)$

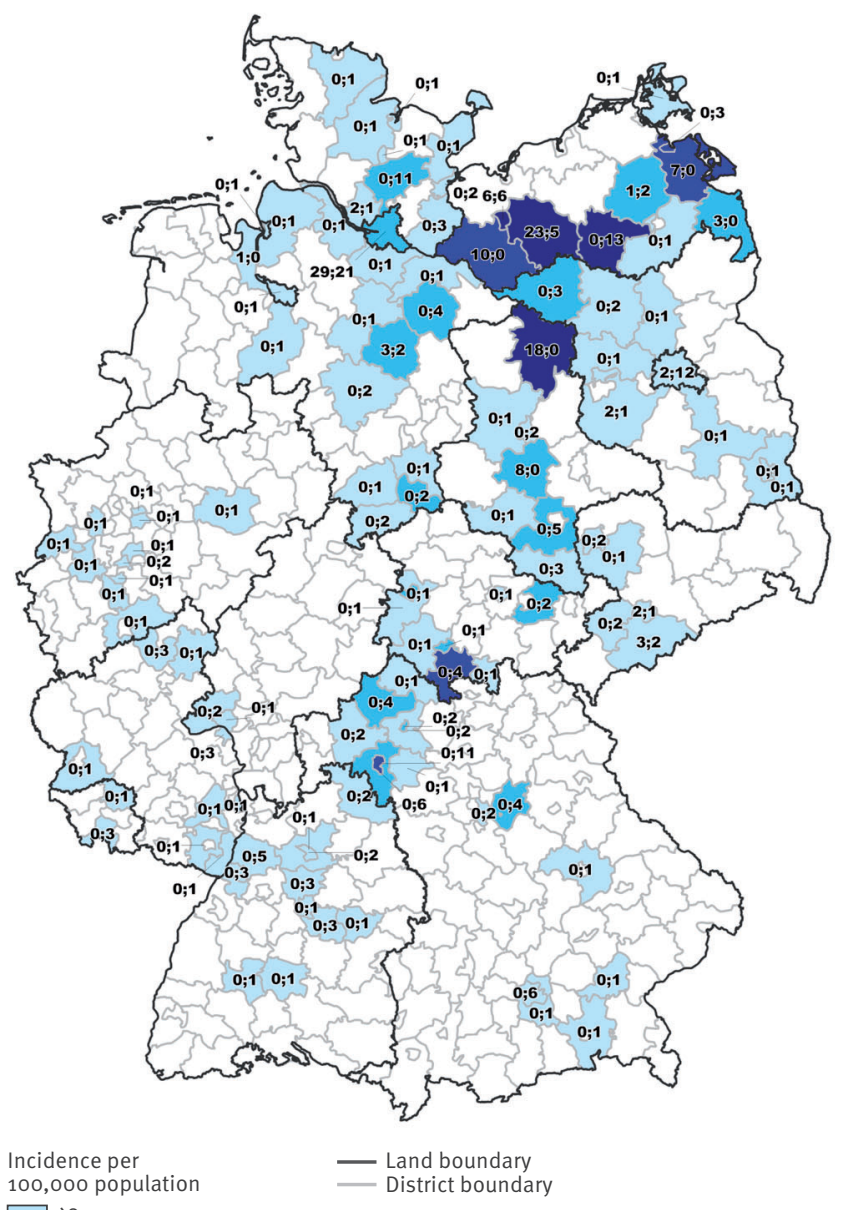

100,000 populatio

$\square>0$

$>2$

First number: number of cluster cases $(n=120)$ Second number: number of sporadic cases $(n=250)$

a Laboratory notifications reported to the Robert Koch Institute, Berlin, Germany.

Data as of 13 October 2010. Cases with onset of symptoms on or after 1 January 2010 or unknown. in the same region within a four-week period suggests a common source of infection or related cause.

Country of infection was reported in 301 (81\%) cases in 2010: Germany was most frequently mentioned $(n=292)$, followed by Thailand $(n=3)$, Egypt $(n=1)$, India $(n=1)$, Portugal $(n=1)$, Romania $(n=1)$, Russia $(n=1)$ and Switzerland $(n=1)$. Serotypes of 15 samples were available: HAdV-8 $(n=7), H A d V-37(n=4), H A d V-19(n=3)$ and one case of HAdV-3, a serotype usually associated with respiratory infections [13].

\section{Cluster cases}

In 2010,120 (32\%) of the 370 cases were linked to 22 clusters (in 2008, there were 46 cases (33\%) in 10 clusters; in 2009, there were 25 cases (15\%) in nine clusters). The 2010 clusters were located across 16 rural and urban districts in eight Laender. The proportion of cases linked to clusters decreased around week 19 (Figure 2). The median age of cases in clusters was 32 years (mean: 33 years, range: 0-90).

\section{Sporadic cases}

There were $250(67.6 \%)$ sporadic cases, of whom 133 were men. The median age was 43 years (mean: 42 years, range: $0-89$ ). Approximately $40 \%$ of all sporadic cases appeared in locations close to clustered cases, which points to a possible connection. However, some sporadic cases were geographically isolated, in regions far from the clusters (Figure 1 ).

Most clusters were notified as being associated with ophthalmological facilities or hospitals. Some were related to outbreaks in child day-care centres or kindergartens, which lowered the median age of cases in clusters significantly (t-test $p=0.004$ ) in comparison with sporadic cases.

\section{Analysis of interviewed cases}

Detailed investigation of 27 cases who were interviewed revealed that the median duration of illness was 18 days (range: 4-84 days); 13 judged the severity of the disease as high or very high (Table 2 ).

A majority $(n=16)$ of the 27 interviewed cases wore either glasses or contact lenses. Among the interviewees, 21 were not aware of any contact with other affected persons. In the two weeks before onset of symptoms, excursions to public places were reported in 13 cases, while 12 stayed in or visited a medical facility (e.g. an ophthalmologist or eye clinics), where mostly eye drops were administered. A total of 11 cases had used communal facilities associated with sport or leisure activities (e.g. in a swimming pool, at the seaside or communal showers) (Table 2).

\section{Discussion}

Compared with the previous two years, an increase of notified adenovirus conjunctivitis cases of more than $250 \%$ was seen in 2010 . Given the delay in reporting, it is likely that case numbers will continue to rise [14]. As 
notification is confined to laboratory-confirmed cases - thus excluding cases that are only clinically diagnosed - it can be assumed that not all cases of adenovirus conjunctivitis are captured and a bias towards severe cases is possible. Although it was not feasible to interview all notified cases, the interviewed cases represented a similar sample in terms of regional, sex and age distribution.
Our findings - showing that the majority of cases who were interviewed was exposed through use of community facilities, excursions to public places within Germany or ophthalmological treatment - are in line with other published investigations $[15,16]$. No direct connection with recently described outbreaks of conjunctivitis in various countries [1-7] could be established due to the few records of German cases with known relevant travel history abroad.

\section{TABLE 1}

Notified adenovirus conjunctivitis cases ${ }^{\mathrm{a}}$, Germany, by Land, 2010 $(\mathrm{n}=370)$

\begin{tabular}{|c|c|c|c|c|c|c|}
\hline \multirow{2}{*}{ Land } & \multicolumn{2}{|c|}{ All cases } & \multicolumn{2}{|c|}{ Cluster cases } & \multicolumn{2}{|c|}{ Sporadic cases } \\
\hline & Number & Incidence ${ }^{c}$ & Number & Incidence ${ }^{c}$ & Number & Incidencec $^{c}$ \\
\hline Baden-Wuerttemberg & 23 & 0.2 & 0 & 0.0 & 23 & 0.2 \\
\hline Bavaria & 45 & 0.4 & 0 & 0.0 & 45 & 0.4 \\
\hline Berlin & 14 & 0.4 & 2 & 0.1 & 12 & 0.4 \\
\hline Brandenburg & 13 & 0.5 & 2 & 0.1 & 11 & 0.4 \\
\hline Bremen & 2 & 0.3 & 0 & 0.0 & 2 & 0.3 \\
\hline Hamburg & 50 & 2.8 & 29 & 1.6 & 21 & 1.2 \\
\hline Hesse & 3 & 0.1 & 0 & 0.0 & 3 & 0.1 \\
\hline Lower Saxony & 24 & 0.3 & 4 & 0.1 & 20 & 0.3 \\
\hline Mecklenburg-West-Pomerania & 81 & 4.9 & 50 & 3.0 & 31 & 1.9 \\
\hline North Rhine-Westphalia & 12 & 0.1 & 0 & 0.0 & 12 & 0.1 \\
\hline Rhineland-Palatinate & 12 & 0.3 & 0 & 0.0 & 12 & 0.3 \\
\hline Saarland & 4 & 0.4 & 0 & 0.0 & 4 & 0.4 \\
\hline Saxony & 13 & 0.3 & 5 & 0.1 & 8 & 0.2 \\
\hline Saxony-Anhalt & 38 & 1.6 & 26 & 1.1 & 12 & 0.5 \\
\hline Schleswig-Holstein & 24 & 0.9 & 2 & 0.1 & 22 & 0.8 \\
\hline Thuringia & 12 & 0.5 & 0 & 0.0 & 12 & 0.5 \\
\hline Total & 370 & 0.5 & 120 & 0.2 & 250 & 0.3 \\
\hline
\end{tabular}

a Laboratory notifications reported to the Robert Koch Institute, Berlin, Germany.

b Data as of 13 October 2010. Cases with onset of symptoms on or after 1 January 2010 or unknown.

c Per 100,000 population.

\section{FIGURE 2}

Notified adenovirus conjunctivitis cases ${ }^{\mathrm{a}}$, by week of symptom onset, Germany, 2010 $\mathrm{b}(\mathrm{n}=303)$

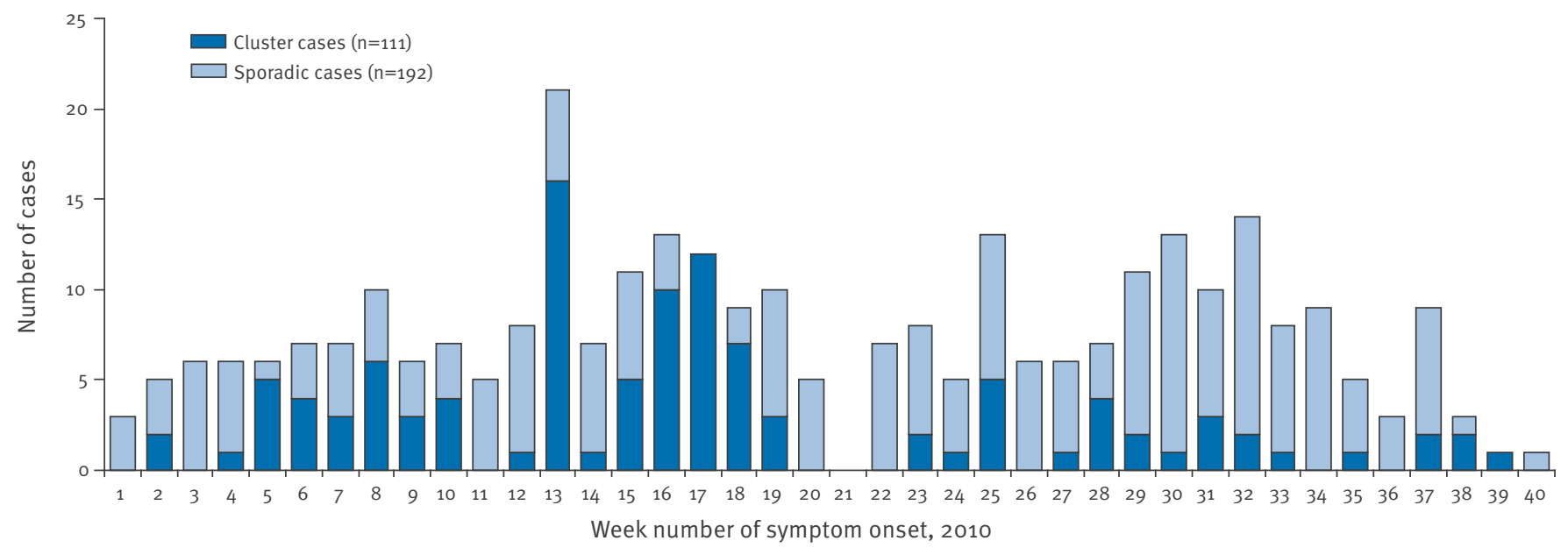

The number of cases in weeks 38-40 was underreported due to reporting delay.

a Laboratory notifications reported to the Robert Koch Institute, Berlin, Germany.

b Data as of 13 October 2010. Date of symptom onset on or after 1 January 2010 was recorded for 303 cases. 
In conclusion, the analysis did not show a disproportionally affected sex or age group, except for outbreaks in child day-care centres and kindergartens [17]. The cause of the increase of notified cases in the country is still unclear, although the majority of infections in clusters was nosocomial. Information about the recent epidemiological developments regarding adenovirus conjunctivitis was shared with German ophthalmologists, with a request to submit conjunctival samples from patients with acute conjunctivitis to the national reference laboratory for serotyping. Improved hygiene measures are recommended, especially in ophthalmological centres $[8,9]$. It would be interesting to know if the increase seen in Germany in the number and

\section{TABLE 2}

Description of interviewed adenovirus conjunctivitis cases, Germany, 2010 $(\mathrm{n}=27)$

\begin{tabular}{|c|c|}
\hline Description & Number of cases ${ }^{b}$ \\
\hline Male / female / not recorded & $10 / 9 / 8$ \\
\hline Median age (range) & 51 years ( $2-79$ years) \\
\hline Optical aid used ${ }^{c}$ & $\begin{array}{l}16 \text { ( } 15 \text { with glasses, } \\
2 \text { with contact lenses) }\end{array}$ \\
\hline \multicolumn{2}{|l|}{ Self-rating of severity of disease } \\
\hline Light & 6 \\
\hline Medium & 6 \\
\hline High & 5 \\
\hline Very high & 8 \\
\hline \multicolumn{2}{|l|}{ Eye affected } \\
\hline Right & 7 \\
\hline Left & 6 \\
\hline Both & 12 \\
\hline Visit to or stay in a medical facility ${ }^{c, d}$ & 12 \\
\hline Ophthalmologist & 7 \\
\hline Eye clinic & $\begin{array}{l}4 \text { (3 outpatients, } \\
1 \text { hospitalised })\end{array}$ \\
\hline Hospital visit & 1 \\
\hline $\begin{array}{l}\text { Optician or other medical professional } \\
\text { or facility }\end{array}$ & 0 \\
\hline $\begin{array}{l}\text { Excursion }^{d} \text { (musical, adventure park, } \\
\text { campsite, lake, city trip, cruise) }\end{array}$ & 13 \\
\hline Overnight stay & 10 \\
\hline Day trip & 10 \\
\hline \multicolumn{2}{|l|}{ Other } \\
\hline $\begin{array}{l}\text { Contact with other people with similar } \\
\text { symptoms }{ }^{d}\end{array}$ & 6 \\
\hline $\begin{array}{l}\text { Visit to communal facility (e.g. } \\
\text { swimming pool or pond, communal } \\
\text { showers, sea, fitness club, sauna) }\end{array}$ & 11 \\
\hline $\begin{array}{l}\text { Use of eye cosmetics or medical } \\
\text { products for eyes }{ }^{d}\end{array}$ & 7 \\
\hline $\begin{array}{l}\text { Use of optical instruments (e.g. } \\
\text { binoculars, camera, } 3 \text { D-glasses) }\end{array}$ & 6 \\
\hline $\begin{array}{l}\text { Sharing of facecloths or towels with } \\
\text { others }^{d}\end{array}$ & 5 \\
\hline
\end{tabular}

a Data as of 13 October 2010. Cases with onset of symptoms on or after 1 January 2010 or unknown.

b Unless otherwise stated.

c Multiple answers allowed.

d In the two weeks before symptom onset. severity of cases of adenovirus conjunctivitis is also seen in other European countries.

\section{Acknowledgements}

The authors thank Tim Eckmanns, Katharina Alpers, Gabriele Laude and Gérard Krause for critical discussions. Susanne Behnke kindly supported the data analysis. We also extend our thanks to all local health officers for their support and to all patients participating in the exploratory interviews.

\section{References}

1. ProMED-mail. Conjunctivitis, internally displaced persons - Pakistan (Sindh). Archive Number 20100923.3439. 23 Sep 2010. Available from: http://www.promedmail.org

2. ProMED-mail. Conjunctivitis - Mexico (03): (Tamaulipas). Archive Number 20100922.3427. 22 Sep 2010. Available from: http://www.promedmail.org

3. ProMED-mail. Conjunctivitis, Viral - China: (Fujian). Archive Number 20100921.3406. 21 Sep 2010. Available from: http:// www.promedmail.org

4. ProMED-mail. Conjunctivitis - Mexico (02): (Guerrero). Archive Number 20100919.3387. 19 Sep 2010. Available from: http:// www.promedmail.org

5. ProMED-mail. Conjunctivitis - Mexico: (Colima). Archive Number 20100903.3155. 3 Sep 2010. Available from: http:// www.promedmail.org

6. ProMED-mail. Conjunctivitis - Uganda And Southern Sudan, Turkey. Archive Number 20100819.2890. 19 Aug 2010. Available from: http://www.promedmail.org

7. ProMED-mail. Conjunctivitis - Bhutan. Archive Number 20100723.2471. 23 Jul 2010. Available from: http://www. promedmail.org

8. Robert Koch Institute (RKI). [Epidemic keratoconjunctivitis and other conjunctivitis caused by adenovirus - RKI Manual on infectious diseases - Manual for physicians (Edition March 2010)]. 2010. Berlin: RKI; 2010. German.

9. Dart JK, El-Amir AN, Maddison T, Desai P, Verma S, Hughes $A$, et al. Identification and control of nosocomial adenovirus keratoconjunctivitis in an ophthalmic department. $\mathrm{Br}$ Ophthalmol. 2009;93(1):18-20.

10. Reed K. Epidemic viral keratoconjunctivitis diagnosis and management. J Am Optom Assoc. 1983;54(2):141-4.

11. Robert Koch Institute (RKI). [Case definitions by the Robert Koch Institute for the reporting of illness, death, and confirmation of pathogens - 2004 edition]. Berlin: RKI: 2003. German,

12. Faensen D, Claus H, Benzler J, Ammon A, Pfoch T, Breuer T, et al.SurvNet@RKI--a multistate electronic reporting system for communicable diseases. Euro Surveill. 2006;11(4):100. pii: 614. Available from: http://www.eurosurveillance.org/ ViewArticle.aspx?Articleld $=614$

13. Lebeck MG, McCarthy TA, Capuano AW, Schnurr DP, Landry ML, Setterquist SF, et al. Emergent US adenovirus 3 strains associated with an epidemic and serious disease. J Clin Virol. 2009;46(4):331-6.

14. Krause G, Altmann D, Faensen D, Porten K, Benzler J, Pfoch T, et al. SurvNet electronic surveillance system for infectious disease outbreaks, Germany. Emerg Infect Dis. 2007;13(10):1548-55.

15. Artieda J, Pineiro L, Gonzalez M, Munoz M, Basterrechea $M$, Iturzaeta A, et al. A swimming pool-related outbreak of pharyngoconjunctival fever in children due to adenovirus type 4, Gipuzkoa, Spain, 2008. Euro Surveill. 2009 Feb 26;14(8). pii: 19125. Available from: http://www.eurosurveillance.org/ ViewArticle. aspx?Articleld $=19125$

16. Schrauder A, Altmann D, Laude G, Claus H, Wegner K, Kohler $\mathrm{R}$, et al. Epidemic conjunctivitis in Germany, 2004. Euro Surveill. 2006 Jul;11(7). pii: 637. Available from: http://www. eurosurveillance.org/ViewArticle.aspx?Articleld=637

17. Robert Koch Institute (RKI). [Analysis of nationally reported notification data on adenovirus conjunctivitis]. Epidemiologisches Bulletin. 2010;37. German. 